\title{
On yawning and its functions
}

\author{
RONALD BAENNINGER \\ Temple University, Philadelphia, Pennsylvania
}

\begin{abstract}
The forms and behavioral correlates of yawning are described, and the phylogenetic and ontogenetic aspects of the act are examined with particular attention to its possible functions. Much evidence supports the view that yawning is an important mediator of behavioral arousal levels, a view that is further strengthened by a review of endocrine, neurotransmitter, and pharmacological mechanisms of yawning: A major function of yawning appears to involve maintenance or increase of arousal when environments provide relatively little stimulation.
\end{abstract}

Why do humans and many other species of mammals, birds, fish, amphibians, and reptiles perform the elaborate behavioral display that we call a yawn? In this review I examine research on yawning by psychologists, pharmacologists, ethologists, and neuroscientists during the past century, paying particular attention to the possible role of yawning in regulating arousal.

\section{Respiration or Arousal?}

Yawning may have different functions in different species, but on the basis of evidence reviewed in this paper I suggest that yawning is one important way of regulating arousal in a remarkable variety of species, including humans. In particular, according to this hypothesis, yawning is likely in situations where wakefulness and the maintenance of arousal level are important, but where the environment is relatively unstimulating. Arousal permits vigilance, attentiveness, and wakefulness, and is typically measured in terms of motor activity and physiological variables such as heart rate, galvanic skin response, electroencephalogram (EEG), or muscle tension.

The Oxford English Dictionary describes yawning in the context of boredom, whereas Gray's Anatomy (Clemente, 1985) and the Encyclopedia of Human Biology (Dulbecco, 1991) do not even show yawning in their indexes. To the extent that they consider it at all, most lay people and physicians appear to believe that yawning is a respiratory phenomenon, a way to get oxygen to the brain (Greco, Baenninger, \& Govern, 1993). In fact, there is meager evidence for this respiratory hypothesis and, on the basis of this review, it appears to be an incomplete explanation at best.

I gratefully acknowledge the ideas and helpful criticism of my colleagues MaryAnn Baenninger, Alan Cowan, Monica Greco, and Luci Paul, as well as the reviewers for this journal. I am also grateful to Byron Campbell at Princeton University, Björn Holmgren and Ruth Urba-Holmgren at the University of Puebla, and Gordon Russell at the University of Lethbridge for their hospitality and intellectual stimulation. A Study Leave and Grants-in-Aid from Temple University were of major assistance in making this work possible. Correspondence should be addressed to R. Baenninger, Department of Psychology, Temple University, Philadelphia, PA 19122 (e-mail: baenning@a)vm. temple.edu).
Ordinary behavioral acts such as yawning, laughing, crying, scratching, belching, sneezing, or sighing are rarely studied per se in any detail by psychologists, except insofar as they communicate or express something to others about an individual's state. Niko Tinbergen, the Nobel Prize winning ethologist, suggested in 1963 that the analysis of any behavioral act should include four basic aspects: (1) the way in which the act develops normally in individuals and the extent to which it becomes modified during ontogeny; (2) its evolution and phylogenetic history; (3) mechanisms underlying the behavior, including its physiology and the stimuli that elicit it; (4) its functions or adaptive value for individuals and species.

In this review, a thorough description of yawning and its behavioral correlates in several species is followed by an examination of its ontogeny, phylogeny, and underlying mechanisms. The thread used to tie all the diverse data and observations together is the basic hypothesis that a major function of yawning is to regulate levels of arousal.

\section{FORMS AND CORRELATES OF YAWNING}

Charles Darwin (1873) described yawning as commencing with

a deep inspiration, followed by a long and forcible expiration; and at the same time almost all the muscles of the body are strongly contracted, including those around the eyes. During this act tears are often secreted, and I have seen them even rolling down the cheeks. (p. 164)

On the basis of X-ray photographs, Barbizet (1958) described yawns in humans as having three phases. In the first phase a progressive, slow opening of the mouth is accompanied by dilation of the thorax, pharynx, and larynx, as well as a lowering of the diaphragm. Although opening of the mouth and deep inspiration also occur at other times, it is only during yawning that the enormous expansion of the pharynx (three to four times normal), the lowering of the hyoid bone, and of the tongue occurs. The glottis is dilated to its utmost in this phase, and is therefore not the cause of the inspiratory sound that may be heard.

In the second phase, the maximal opening of the mouth produces contraction of lip dilators, eyelid contraction 
(often causing occlusion of the eyes), and nostril dilation, together with wrinkling of skin at the base of the nose, and eyebrow lifting. Maximal dilation of the pharynx occurs, and thoracic capacity is increased further by stretching. Tears and saliva are frequently secreted, and vasoconstriction in the digits and cardiac acceleration have also been reported (Greco \& Baenninger, 1991; Heusner, 1946; Proctor, 1964). Such measures are clearly related to arousal as defined by polygraph recordings.

Inspiration ceases abruptly in the third phase and expiration is slow and noisy; an "aah" sound may originate in the larynx, the pharynx returns to normal size, the mouth closes rapidly, and the facial muscles return to normal. Barbizet (1958) reported that the whole sequence lasts $4-7 \mathrm{sec}$, a figure confirmed in humans by Provine (1986) and by Baenninger and Greco (1991).

The same basic sequence appears in all major classes of vertebrates, and in my own studies of yawning in fish and mammals, I have adopted it as a criterion (i.e., slow opening of the mouth, with inspiration in mammals, and a more rapid closing and exhaling after several seconds). Although we cannot be certain that a behavioral sequence is equivalent in species as different as Siamese fighting fish, domestic dogs, cats, walruses, lions, and humans, the use of the same descriptive word simplifies communication.

Stretching of the limbs often accompanies yawning in humans, depending on whether they are standing, seated, or lying down. In some quadrupeds, such as rats and dogs, stretching of the forelegs occurs. Ferrari, Floris, and Paulesu (1955) reported a stretch/yawn syndrome in dogs, and this syndrome was also found in rats (Gessa, Pisano, Vargiu, Grabai, \& Ferrari, 1967) and guinea pigs (Rodriguez, Serra, Terrasawa, Goldfoot, \& DeWied, 1981). Donovan (1978) reported the stretch/yawn syndrome in human males (accompanied by penile erections and even ejaculations).

Penile erection has been observed to accompany druginduced yawning in several mammalian species, including rabbits and rats (Bertolini, Vergoni, Gessa, \& Ferrari, 1969; Huston, 1971; Mogilnicka \& Klimek, 1977). Phoenix and Chambers (1982) found penile erections associated with yawning in rhesus monkeys (both normal and pseudohermaphrodite) in response to synthetic testosterone injections; these authors also reported that yawning by female rhesus monkeys was elicited by testosterone. More recently Melis, Stancampiano, Lai, and Argiolas (1995) reported that nitroglycerin, a potent vasodilator, induced both yawning and penile erections in male rats. Whether this association with penile erections also exists in yawns that are spontaneous is not yet clear, but the association of arousal and yawning is emphasized by these findings.

Finally, Ushijima, Yamada, Inoue, Tokunaga, and Furukawa (1984) reported that tongue protrusion accompanied yawning by rats. Van Woerden et al. (1988) also found tongue protrusion, grimacing, and jaw opening in the yawns of human fetuses. Salamone, Lalies, Channell, and Iversen (1986) distinguished yawning in rats from gaping, which involves rapid opening and closing of the mouth with the teeth visible.

\section{THE CONTEXT OF YAWNING}

Particular times of day are associated with yawning, which raises the possibility of an endogenous temporal rhythm. Anias, Holmgren, Urba-Holmgren, and Eguibar (1984) found that light-to-dark transitions were associated with daily peaks of yawning by laboratory rats. The fact that yawning increased well before dark onset suggested to these authors that yawns were not simply induced by darkness, and that a genuine circadian rhythm existed. In humans the transition from light to dark is also associated with frequent yawning but, unlike rats, there is also a peak in yawning in the transition from dark to light. Provine, Hamernik, and Curchack (1987) found that yawning by college students was most frequent during the hour just before sleeping and after morning awakening. Greco et al. (1993) replicated this finding but also found a smaller peak in early afternoon before the sleepiness peak reported by Mavjee and Horne (1994).

Baenninger, Binkley, and Baenninger (1996) reported that nocturnal awakening was associated with yawning in adult subjects who were wearing activity monitors. Daily transitions from inactivity to activity (early morning) and from activity to inactivity (late evening) were strongly associated with yawning. Their subjects did not yawn when they were actually lying in bed waiting to fall asleep, and their yawning before retiring to bed can be interpreted as attempts to maintain wakefulness or arousal.

Although these regular daily variations in yawning frequency might represent an endogenous rhythm, an alternative explanation appears to be more parsimonious and general. If yawning occurs in anticipation of regular daily events that require increased arousal, we would expect yawning after sleeping, during sedentary activities that require arousal or vigilance (such as attending lectures and driving a car, as reported by Greco et al., 1993), and as a way of maintaining wakefulness in the late evening. As noted, these are precisely the contexts in which frequent yawning has been found. Also supporting the hypothesis that yawning is a means of increasing or maintaining arousal are the reports by Baenninger (1987) and Holmgren et al. (1991) that zoo and laboratory animals yawn before their regular feeding times, apparently in anticipation of this major event of their days in captivity. Perhaps for similar reasons, Koch, Montagner, and Soussignan (1987) found that children in kindergarten showed daily peaks of yawning at the beginning and just before the end of their school days (when maintaining wakefulness may be difficult, and free time beckons).

\section{PHYLOGENETIC ASPECTS OF YAWNING}

The daily lives of carnivorous mammals are characterized by large variations in arousal level, from seden- 
tary tranquillity to stalking, chasing, and killing prey. Methods for achieving rapid and frequent changes in states of arousal should be present among carnivores. By contrast, the lives of grazing herbivores are relatively invariant; the difficulty of deriving enough protein and other nutrients from grasses requires that herbivorous mammals spend most of their waking time eating. In general, carnivores yawn much more frequently than herbivores, as the arousal hypothesis would predict. In 35 h of observation, Greco (1992) never saw giraffes yawn, perhaps because of their unique respiratory and circulatory adaptations. Barbizet (1958) claimed that yawning was virtually absent in herbivores, but species as different as horses and hippopotamuses clcarly do yawn on occasion, and Craemer (1924) reported it in both Perissodactyla (e.g., horses, tapirs, rhinoceroses) and Artiodactyla (e.g., swine, deer, antelope, cattle, sheep). I have observed frequent yawning among the horses that wait along Central Park South to give carriage rides to tourists in New York City.

Among the carnivores, yawning is frequent in the fissipeds, both the Felidae (cat family) and Canidae (dog family) (Baenninger, 1987; Ferrari et al., 1955; Konorski, 1967; Marini, 1981). It has also been found in pinnipeds (seals, sea lions, walruses). In fur seals (ArCtocephalus forsteri) and walruses (Odobenus rosmarus), Miller (1975) reported that yawning was associated with erecting the mystacial vibrissae. Among other mammalian orders, yawning has been reported in rodents (rats by Anias et al., 1984; guinea pigs by Rodriguez et al., 1981), lagomorphs (rabbits, Opp, Obal, \& Krueger, 1988), and various species of nonhuman primates (Baenninger, 1987; Deputte, 1994; Hadidian, 1980; Louboungou \& Anderson, 1987; Phoenix \& Chambers, 1982; Redican, 1975). To the best of my knowledge, there have been no formal reports on yawning by any species of the Chiroptera (bats), Marsupialia (opossums, kangaroos), Insectivora, Edentata (sloths, anteaters, armadillos), Cetacea (whales, dolphins, porpoises), Monotremata (echidnas, platypus), Proboscidea (elephants), or Sirenia (manatees, dugongs). Yawning may occur in all these orders too, but it has not been noted in published observations.

Behavior leaves no fossils, so unambiguous evidence on how and why yawning evolved is impossible to obtain. Skulls of extinct species can tell us only whether yawning was possible, not whether it occurred. We can know only the pattern by which traits appear, or do not appear, in species that exist now, which may help us to derive the phylogenetic history of a behavioral trait such as yawning. If all existing species in each genus, family, and order of mammals, birds, fishes, amphibians, and reptiles had been observed to yawn, we could trace the act back to the primitive chordates from which all vertebrates evolved. Sharks and rays are among the most primitive members of the phylum Chordata, but yawning has not been reported in them.

In fish, yawning has been reported in species as diverse as Siamese fighting fish, Betta splendens (Baenninger, 1987), damsel fish, Eupomacentrus partitus
(Myrberg, 1972), and jewel fish, Microspathodon chrysurus (Rasa, 1971). Yawning has been seen in reptiles such as tortoises (Luttenberger, 1975), and in turtles, lizards, and crocodiles (Craemer, 1924). Barthalmus and Zielinski (1988) found yawning in northern water snakes, Nerodia sipedon. Among birds, yawning has been reported in ostriches (Sauer \& Sauer, 1967), and I have observed it in herring gulls; Dumpert (1921) asserted that it is universal in the class Aves. Craemer reported yawning by toads and frogs, accompanied by bending and stretching of the hind legs, but it has not been reported in other amphibians such as newts or salamanders. Thus, although the published observations are extremely incomplete, yawning appears to occur in all classes of vertebrates. At the very least, this suggests that it has important and basic functions, but mere occurrence of a behavioral trait, even in a variety of species, does not prove that it is adaptive.

Although we may know relatively little about how natural selection has affected yawning, the work of Holmgren and Urba-Holmgren and their collaborators (1991) makes it clear that artificial selection can modify the frequency of yawning. Selective breeding resulted in a strain of rats that yawns frequently (nearly 25 yawns/ hour) and a strain that yawns very little (less than once/ hour) by the 25th generation. Differences between frequent (HY) and infrequent (LY) populations were already apparent by the $\mathrm{F} 3$ generation.

\section{ONTOGENETIC ASPECTS OF YAWNING}

Blanton (1917) reported yawning by neonates within 5 min after birth, almost as if they were waking up after delivery from their uterine environment. Taylor-Jones (1927; see also Gill, White, \& Anderson, 1984) confirmed that newborns yawn a few minutes after taking their first breath. It is possible that neonatal yawns, like adult yawns upon awakening, may serve to increase arousal. Feldman, Brody, and Miller (1980) reported that yawning was more frequent in female neonates than in males.

Perhaps even more remarkable is the report by Smotherman and Robinson (1987) that rat fetuses showed yawning at Day 20 of gestational development. Van Woerden et al. (1988) observed regular mouth movements in utero during certain human prenatal phases: yawns, grimaces, and tongue protrusion were clearly seen. Sherer, Smith, and Abramowicz (1990) also observed yawns in a 20 -week-old human fetus. The fetal environment is presumably less stimulating than the postnatal one; like adult yawns in boring situations, fetal yawns may serve to increase arousal for some purpose.

Prenatal yawns could also be responses to uterine chemistry, or to the internal physiological state of the fetus. Such yawns are incompatible with the "respiratory hypothesis." Although the fetus requires oxygen and must expel carbon dioxide, it does not do so by using the adult respiratory mechanism. Fetal lungs are incompletely developed until near term, and external stimula- 
tion is often necessary at the time of birth in order to start their normal operation. Thach and Taeusch (1976) observed sighing in newborn human infants and suggested that it served as an inflation-augmenting reflex for the newly functioning lungs. Proctor (1964) pointed out that many respiratory physiologists interpret sighing functionally as a "small yawn."

Fetal mouth movements, grimacing, and stretching might be the means by which neonates are able to produce normally integrated yawns within minutes after being born. Perhaps it is only postnatally that yawning becomes functional (whether that function proves to be arousal regulation or not). Human data on this point are lacking, but Holmgren et al. (1991) found that male rats increased their frequency of yawning during the 1 st year of life. Neonatal yawning is unlikely to be an imitative or contagious response to adult yawning, and Piaget (1951) asserted that yawns elicited by seeing another individual yawn did not occur until the 2nd year of life. During the 1st year, yawns appear to be spontaneous; imitative or contagious yawning may prove to be an interesting developmental marker.

There have been no reports of age-related changes in the actual form of human yawning, but it is clear that there are developmental changes in the daily pattern of yawning, as well as in its frequency, its eliciting stimuli, and whether it is under voluntary control. Troisi, Aureli, Schino, Rinaldi, and DeAngeli (1990) found that male macaques begin to yawn much more frequently than females when androgen levels rise at sexual maturity from juvenile to adult levels, a difference that is then maintained throughout life (Deputte, 1994). In nonhuman primates, it appears that males yawn with increasing frequency as they grow older (Chambers \& Phoenix, 1980; Deputte, 1994; Hadidian, 1980), perhaps because maintenance of arousal levels becomes more difficult for aged monkeys. Hadidian found that the dominant male in wild troops yawned most frequently. It is not clear whether this is because increased arousal and vigilance are required to be an alpha male, or because dominant individuals have higher androgen levels, or because yawns are used by dominant males as threat displays.

During their 1st year of school, children yawn five times as frequently as they did in nursery school (Koch et al., 1987). At this important juncture in their lives, children are expected to reduce their level of physical activity during school hours and to conform to school rhythms and constraints. Yawning is a familiar sight to most teachers, even those who are not boring, and would be expected if yawning is a way to maintain arousal in a sedentary environment providing relatively low levels of stimulation.

\section{MODIFIABILITY OF YAWNING}

Baenninger, Binkley, and Baenninger (1996) found that some of their adult subjects reliably yawned 30 times each day, whereas others did so only once or twice. In that study, those who yawned relatively infrequently tended to be more active than frequent yawners. If yawning is a way of regulating activity or arousal, it is possible that some people have learned to regulate arousal by yawning whereas others have not, using other means instead. To what extent is the rate of yawning by individuals modifiable?

Provine (1986) has maintained that yawning is a "stereotyped action pattern" that is elicited by the sight of someone yawning, or by reading, thinking, or talking about yawning. Earlier ethologists referred to such acts as "fixed action patterns," emphasizing that they were fixed not only in their topography but also in the small number of stimuli that would elicit them. If Provine is correct, yawning should be relatively fixed in its form and should appear only in response to certain stimuli. To my knowledge, there have been no reports of Pavlovian conditioning in which previously neutral stimuli come to elicit yawning.

The extent to which the frequency of action patterns or operant acts may be controlled by their consequences has interested American psychologists for many years. Thorndike (1911) successfully trained cats to lick or scratch when those acts resulted in release from a box. Can yawning similarly be brought under the control of its rewarding or punishing consequences? Konorski (1967) found that food reward of "true" yawning was nearly impossible in dogs, although what he termed "pseudoyawns" (of short duration) did increase in frequency when they were rewarded. Louboungou and Anderson (1987) used food rewards in training pigtail macaques (Macaca nemestrina) to yawn more frequently, at rates up to 150 times per hour. Anderson and Wunderlich (1988) found a similar result in Macaca tonkeana. Small (1977) found that frequency of human yawning could be changed in the laboratory by using a complex training procedure in which subjects imagined a contingency between yawning and certain visual images.

Operant conditioning may also reduce the frequency of acts followed by aversive events, as in punishment. Tsunetomo (1979), a Japanese samurai, remarked that "it is bad taste to yawn in front of people" and suggested that stroking the forehead upward or licking the lips with mouth closed were successful in inhibiting yawns. Most people appear to have learned techniques to suppress or inhibit their own yawns in interviews, conversations, or lectures where polite behavior is expected. In fact, the study of yawning in the experimental laboratory has been hampered by subjects' unwillingness to yawn in the presence of experimenters (Baenninger, 1987; Greco \& Baenninger, 1989). Social factors may inhibit overt yawning, but the motor pattern still occurs and the result is a closed-mouth, teeth-clenched yawn in which activity of jaw muscles can usually be seen. Greco (1992) punished her subjects for yawning during a boring simulated driving task by withholding money. Subjects reduced their yawning frequency, but also made more careless driving errors, a result that lends support to the hypothesis that yawning helps to maintain the level of arousal or vigilance. 


\section{PHYSIOLOGICAL MECHANISMS OF YAWNING}

Many hours may be spent in waiting for a subject to yawn spontaneously. Behavioral pharmacology has provided important knowledge about the mechanisms of yawning, in part because hormones or drugs may reliably elicit yawning. Whether drug-induced yawns are identical to those that occur without drugs remains a concern in interpreting this research.

\section{Drugs That Induce Yawning}

Withdrawal from opiate narcotics is associated with frequent yawning in human adults (O'Brien, 1976), as well as in infants undergoing withdrawal from maternal addiction to heroin, morphine, or methadone (Rudolph, Barnett, \& Einhorn, 1977). Yawning may be elicited in rats by cholinomimetic drugs such as physostigmine and pilocarpine (Urba-Holmgren, Gonzalez, \& Holmgren, 1977; Yamada \& Furukawa, 1980). Physostigmine inhibits acetylcholine metabolism, and pilocarpine is a cholinergic agonist; both produce yawning in infant rats, with a maximum frequency of 8-10 yawns in $15 \mathrm{~min}$ (each lasting 3-4 sec). Antagonistic effects of atropine and scopolamine were found by Ferrari et al. (1955) in their original work, indicating that yawning is cholinergically mediated (because of its susceptibility to muscarinic blockers).

Both cholinergic (Cowan, 1978) and dopaminergic (Mogilnicka \& Klimek, 1977) components were subsequently discovered. Low doses of apomorphine or other dopamine agonists (Holmgren \& Urba-Holmgren, 1980; Marini, 1981; Mogilnicka \& Klimek, 1977) induce yawning with stretching, chewing movements, and penile erection in male rats. Mogilnicka and Klimek suggested that treatment with low doses of dopamine agonists activates presynaptic inhibitory dopamine receptors (so-called autoreceptors). These are more sensitive to dopamine and dopamine agonists than are postsynaptic receptors. Thus, low dopamine doses may stimulate these autoreceptors, inhibiting synthesis and release of dopamine, thereby decreasing dopaminergic transmission.

Holmgren and Urba-Holmgren (1980) proposed that two sets of dopaminergic and cholinergic neurons, localized in the brain, are organized in series with the former tonically inhibiting the latter. Cholinergic neurons exert a direct excitatory influence on a hypothesized central motor pattern generator for yawning. In this model, low doses of apomorphine, by activating dopamine presynaptic autoreceptors, produces yawning by disinhibition of the cholinergic excitatory neurons. Higher doses of dopamine agonists directly inhibit the cholinergic neurons, suppressing yawning.

Negative and positive modulating influences by noradrenergic, glutamatergic, and serotonergic mechanisms have also been demonstrated (Holmgren \& Urba-Holmgren, 1980; Lanthorn \& Isaacson, 1979; Urba-Holmgren, Holmgren, Rodriguez, \& Gonzalez, 1979: Yamada \& Furukawa, 1981). Dourish and Cooper (1991) proposed another model for the neural control of yawning that involved excitatory cholinergic, peptidergic, and serotonergic influences, together with dopamineric and noradrenergic inhibitory influences. Thus, this apparently simple instinctive act may be under the control of a complex set of neurotransmitter mechanisms.

\section{Hormones}

Since 1955, when Ferrari et al. discovered that injection of ACTH into cerebral ventricles of dogs produced a syndrome of yawning and stretching, they and their colleagues have replicated (Argiolas, Melis, Stancampiano, \& Gessa, 1989; Gessa et al., 1967) and extended this finding to a number of other hormones, such as MSH (Ferrari, Gessa, \& Vargiu, 1963); Laping and Ramirez (1986) found that prolactin induced both yawning and stretching in male rats.

Argiolas, Melis, and Gessa (1986) found that oxytocin, another pituitary hormone, was an extremely potent inducer of yawning and penile erection in rats. Argiolis, Melis, Stancampiano, and Gessa (1989) found that injection of oxytocin and related peptide hormones into the lateral ventricles of rats produced both yawning and penile erection, concluding that central oxytocin receptors that mediate the expression of both penile erection and yawning are structurally related to those receptors present in uterus and mammary glands.

Numerous other experiments have confirmed the association of hormone-induced yawning and penile erections (Berendsen \& Nickolson, 1981; Gower, Hemmie, Berendsen, Princen, \& Broekkamp, 1984; Holmgren, Urba-Holmgren, Trucios, Zermeno, \& Eguibar, 1985; Serra, Collu. Loddo, Celasco, \& Gessa, 1983). Spontaneous yawning in humans, dogs, and rats may be accompanied by stretching, but is not normally accompanied by any overt signs of sexual excitement. Sexual arousal has been reported in some case reports of drugrelated yawning. Donovan (1978) reported that both intracranial ACTH and MSH elicited the stretch/yawn syndrome in human males, accompanied by erections and even ejaculations. Modell (1989) reported the case of a 30-year-old woman taking fluoxetine (Prozac, a serotonin reuptake blocker) whose frequent yawning was associated with such signs of sexual arousal as clitoral engorgement and moderate orgasms. No relationship between estrogen and yawning has been found in rats (Holmgren, Urba-Holmgren, Aguiar, \& Rodriguez, 1980) or monkeys (Phoenix \& Chambers, 1982), whereas in guinea pigs estrogen antagonizes yawning induced by apomorphine (Rodriguez et al., 1981).

Chambers and Phoenix (1980) found a positive correlation between testosterone levels and rate of spontaneous yawning by aging male rhesus monkeys. Generally among nonhuman primates, males yawn considerably more frequently than do females (Bertrand, 1969; Deputte, 1978, 1994; Goy \& Resko, 1972; Hadidian, 1980; Hall \& DeVore, 1965; Redican, 1975). Deputte (1994) reported that mangabey males yawned six times more often than females, whereas in macaques the ratio was 
eight times more. Such results suggest the possibility that yawning (or gaping) may serve as an aggressive threat display, since in these primate species the canine teeth of males are much more prominent than in females. Troisi et al. (1990) found that yawns were associated with intermale threats. Packer (1979) observed that an adult male baboon yawned less frequently after one of its prominent canine teeth broke. In our species, Schino and Aureli (1989) reported no differences between yawning frequency of males and females; the canine teeth of human males are not noticeably larger or more threatening than those of females.

Yawning appears to be associated with hormonally induced stretching, gaping, and penile erection, which are clear signs of increased arousal. It is not clear which comes first, but peptide and steroid hormones appear to be involved in yawning that is associated with both aggressive threats and sexual arousal.

\section{Yawning and Respiration}

Greco et al. (1993) found that most of their survey respondents believed that too little oxygen or too much carbon dioxide were the main causes of yawning (i.e., the respiratory hypothesis). At best, the respiratory hypothesis is incomplete-for example, both boredom and seeing other people yawn are potent causes of yawning. Breathing faster or more deeply is a more effective way of increasing oxygen intake and expelling carbon dioxide than a single deep inspiration, especially since a period of apnea usually follows a yawn (Hauptmann, 1920; Lehman, 1979). Nevertheless, the hypothesis has been widely held since its mysterious origins in the 19th century (Dumpert, 1921).

Yawning is more complex than simply opening the mouth and breathing in deeply, although some of the physiological results are similar. Greco and Baenninger (1991) found that wide opening of the mouth and deep breaths produced changes in skin conductance and heart rate that were initially similar to changes produced by full yawns, but the patterned action of a yawn may be controlled by a different neural mechanism. Gschwend (1977) reported on a patient with a transsecting glioma of the pons who was able to yawn normally even though he was unable to open or close his mouth voluntarily.

Periods of apnea are not followed by compensatory yawning after breathing is resumed, as the respiratory hypothesis would require. In mammals, the normal pattern of breathing includes relatively shallow breaths interrupted by occasional sighs. In the absence of sighs or deep breaths, this shallow breathing pattern may result in areas of atalectasis (similar to collapse), with diminished compliance and hypoxemia in the alveoli of the lungs (Mead \& Collier, 1959). Thet, Clerch, Massaro, and Massaro (1979) found that a single large inflation removed areas of atalectasis that occurred during $2 \mathrm{~h}$ of normal ventilation in excised rat lungs, a finding replicated by Nicholas, Power, and Barr (1982).

The clearest evidence against the respiratory hypothesis comes from a laboratory study by Provine, Tate, and
Geldmacher (1987) in which subjects breathed air mixtures containing more than normal amounts of carbon dioxide $(3 \%-5 \%)$; their rate of breathing increased but the frequency of yawning was unaffected. Exercise that doubled their rate of breathing also had no effect on subjects' yawning frequency. Conversely, subjects breathing pure oxygen did not show decreased yawning. It seems clear that yawning is something more than an odd kind of respiration.

\section{Cerebral Blood Flow}

In 1881, Russell (cited in Heusner, 1946, p. 159) proposed that yawns may "effect a stimulation of the brain through increased activity of the circulation." Changes in intracerebral flow of blood are almost certain to bring about changes in cortical arousal. Decreased intracerebral blood flow produced by hemorrhage (Barbizet, 1958 ) and motion sickness (Johnson \& Jongkees, 1974) are accompanied by increased yawning. Karasawa et al. (1982) monitored cerebral blood flow and EEG of thrombosis patients and found that yawning occurred under two circumstances: when EEG indicated low cortical arousal and when partial pressure of oxygen in the carotid artery decreased. Such a pattern is certainly consistent with the hypothesis that yawning affects arousal by bringing about an increase in intracerebral blood flow.

Askenasy (1989) has proposed an elaborate way in which the act of yawning might increase cerebral blood flow. According to this hypothesis, inhaling stretches bronchial muscles and stimulates vagus nerve terminals that bring about dilation of arterioles via cholinergic pathways. This decreases resistance to peripheral circulation and enhances blood flow. Gaping of the jaw contracts the lateral pterygoid and soleus muscles, which empties rich venous plexuses contained in them (the plexuses are sometimes referred to as "peripheral hearts"). This action of the jaw muscles enhances venous return, which promotes blood hyperoxygenation and thus stimulates cerebral blood flow (including the ascending reticular activating system). Although this mechanical hypothesis provides a plausible explanation of how yawning may be related to arousal, any direct evidence for it is still lacking.

\section{Middle and Inner Ear Events}

Laskiewicz (1953) proposed that yawning served to adjust air pressure in the middle ear. However, although people may be observed to yawn in high-speed elevators, especially if they have respiratory infections that block the Eustachian tube, it is a cumbersome alternative to the simple act of swallowing (which also opens the valve arrangement in the Eustachian tube).

Involvement of the inner ear is suggested by the fact that motion sickness is accompanied by yawning (Graybiel \& Knepton, 1976; Johnson \& Jongkees, 1974), as is car sickness (Nakanishi, Hinoki, Ito, Izumikawa, \& Baron, 1980). Deaf-mute people with congenitally incomplete labyrinths of the inner ear are immune to motion sickness and the accompanying yawning (Johnson \& Jong- 
kees. 1974). Motion-produced sickness is associated with pooling of blood in lower parts of the body and, as these authors suggested, yawning may therefore be a way of compensating for decreased intracranial blood circulation by increasing venous return to the heart. Thus, inner ear involvement may lend further support to the idea that yawning is a way of regulating cerebral blood flow (and thus arousal).

\section{The Tonsillar Hypothesis}

McKenzie (1994) proposed that yawning is a reflex muscular contraction that ensures intermittent evacuation of the palatine tonsillar fossae, thereby ensuring that the tonsils are exposed to new antigens and preventing excessive accumulation of foreign material, microorganisms, and inflammatory products. Since the palatine tonsils appear to lack an evacuating reflex, but are located in a dark, moist environment where they are exposed to masticated food and bacteria, they should be chronically infected. They are not, and McKenzie suggested that yawning may be a reflex to clear the tonsils of infectious materials. He provided no data relevant to his ingenious suggestion. In an unpublished study I found no relationship between yawning frequency and whether respondents had tonsils or not.

\section{ENVIRONMENTAL CAUSES OF YAWNING}

\section{Transitions}

Troisi et al. (1990) found that yawns by Macaca fascicularis and M. fuscata were associated most often with transitions between sleep and waking. Myrberg (1972) found that damselfish Eupomacentrus partitus yawned during transitions between their different activities, while Baenninger (1987) reported that zoo-housed lions Panthera leo and mandrills Papio sphinx yawned more frequently just before feeding time, a result that was replicated in laboratory rats by Holmgren et al. (1991). Moyaho, Eguibar, and Diaz (1995) found that yawning, grooming, and emotional reactivity of laboratory rats were all associated with arousal variation. Breeders and owners of dogs and cats have reported that yawning and stretching normally occur during transitions from resting to waking or exercising. Deputte (1994) found that $90 \%$ of yawns were associated with rest/activity transitions during nearly $800 \mathrm{~h}$ in which he observed two species of Old World monkeys.

In humans, frequent yawning follows awakening in the morning or attempting to stay awake in late evening (Greco et al., 1993; Provine et al., 1987). Awakening during the night was also followed by yawning and subsequent activity (Baenninger et al., 1996). Subjects in this last study wore activity monitors for 2-week periods and almost invariably increased their activity rate within 15 min after yawning. Dumpert (1921) reported that patients yawn when returning to conscious awareness after being hypnotized. Finally, driving automobiles requires frequent transitions between active concentration and passive boredom. Subjects who kept activity logs reported to Greco et al. that yawning was associated with driving more than with any other daytime activity except sitting in lectures. Although none of the studies is conclusive by itself, there seems little doubt that transitions in activity are associated with yawning. Whether yawning causes arousal or activity changes or such changes cause yawning is not yet clear.

\section{Threats, Conflict, or Stress}

Baenninger (1987) found that male Siamese fighting fish, a species with an elaborate threat display, yawned frequently during aggressive encounters but never when alone. Darwin noted that "baboons often show their passion and threaten their enemies ... by opening their mouths widely as in the act of yawning" $(1873$, p. 136). Troisi et al. (1990) found that in addition to sleep/waking transitions, yawns by $M$. fascicularis and $M$. fuscata were associated with intermale threats, conflict, and anxiety, findings replicated by Mastripieri, Schino, Aureli, and Troisi (1992). These authors suggested that yawning may be an example of a displacement act reflecting psychosocial stress, a state that is certainly congruent with arousal.

Deputte (1994) reported that "emotion" yawns followed social interactions, particularly in tense confrontations between males, while Hadidian (1980) found that dominant males yawned much more than others in the macaque troops he observed. Findings in other nonhuman primate species also support the association of yawning with arousing encounters between males (Hall, 1962; Hinde \& Rowell, 1962).

\section{Boredom and Sleepiness}

It is not surprising that boredom, inactivity, and lack of interest are associated with yawning. Students in lecture classes yawn at a much higher rate than those in aerobics classes, dining halls, or libraries (Baenninger. 1987). More frequent yawning is associated with viewing uninteresting, repetitive stimuli than with viewing interesting stimuli (Provine \& Hamernik, 1986). If maintaining wakefulness is important, yawning may be a way to remain awake and attentive, even when physical or mental stimulation is lacking.

Existing data do not unambiguously support an association between yawning and sleepiness. Skorzewska et al. (1993) found no significant correlations between sleepiness scores of subjects who were injected with scopolamine and their yawning frequency. Baenninger and Greco (1991) found no correlations between frequency of yawning by laboratory subjects and the number of hours slept the previous night.

During actual sleep, yawning apparently does not occur at all, according to Lal, Grassino, Thavundayil, and Dubrovsky (1987). This is what the arousal hypothesis would predict, since the struggle to maintain wakefulness has been abandoned by a sleeping individual. Sleep includes different phases, however, and during REM or "paradoxical" sleep, the EEG record shows a cortical arousal pattern that is more similar to the wak- 
ing state than to the patterns during slow wave sleep. If the arousal hypothesis of yawning is correct, we might expect to find yawns occurring in conjunction with transitions from slow wave to REM sleep phases. This would be an important test of the arousal hypothesis.

\section{Contagion, Suggestion, or Social Facilitation}

Although the contagiousness of yawning is apparent in social situations, this phenomenon is difficult to study in the laboratory because subjects appear reluctant to yawn when being observed (Greco \& Baenninger, 1989). Laboratory subjects did not yawn in response to seeing live or televised actors yawn while reading uninteresting material (Baenninger, 1987). In an unreplicated study, Moore (1942) reported some contagious yawns in the laboratory, in church services, and during a film. He also found that some blind subjects yawned in response to an audio recording of yawns. It is not known whether contagious yawning requires awareness of the stimulus, although Heusner (1946) asserted that it could be activated at "subconscious levels." Thinking or reading about yawning is a stimulus for the actual performance of the act (Baenninger \& Greco, 1991; Greco \& Baenninger, 1991; Provine, 1986).

\section{Yawning and Arousal}

The hypothesis underlying this review is that an important function of yawning is to modify levels of cortical arousal, especially in situations where there is little external stimulation and where a low level of arousal could be costly or dangerous. Most of the findings reviewed have been consistent with this hypothesis. Yawning occurs in anticipation of important events (Baenninger, 1987) and behavioral transitions (Deputte, 1994; Greco \& Baenninger, 1991; Greco et al., 1993; Koch et al., 1987; Moyaho et al., 1995), and also reliably precedes activity increases (Baenninger et al., 1996). Effects of cerebral blood flow, as well as hormones and drugs, are consistent with an association of yawning and arousal, especially with respect to sexual arousal, intermale threat displays, and conflict.

Maintaining or attaining a particular level of arousal is an important matter in the life of most vertebrates, and yawning, to the extent that it serves as a means for doing so, should be seen as an important part of adaptive behavior. The physiological, ontogenetic, and phylogenetic findings reviewed here are consistent with this view.

\section{REFERENCES}

ANDERSON, J. R., \& WundeRlich, D. (1988). Food-reinforced yawning in Macaca tonkeana. American Journal of Primatology, 16, 165 169.

Anias, J., Holmgren, B., Urba-Holmgren, R., \& Eguibar, J. R. (1984). Circadian variation of yawning behavior. Acta Neurobiologiae Experimentalis, 44, 179-186.

Argiolas, A., Melis, M., \& Gessa, G. (1986). Oxytocin: An extremely potent inducer of penile erection and yawning in male rats. European Journal of Pharmacology, 130, 265-272.

argiolas, A., Melis, M. R., Stancampiano, R., \& Gessa, G. L.
(1989). Penile erection and yawning induced by oxytocin and related peptides--Structure-activity relationship. Peptides, 10, 559-563.

ASKENASY, J. J. (1989). Is yawning an arousal defense reflex? Journal of Psychology, 123, 609-621.

BAENNINGER, R. (1987). Some comparative aspects of yawning in Betta splendens, Homo sapiens, Panthero leo, and Papio sphinx. Journal of Comparative Psychology, 101, 349-354.

Baenninger, R., Binkley, S., \& Baenninger, M. (1996). Field observations of yawning and activity in humans. Physiology \& Behavior, 59, 421-425.

BaEnNinger, R., \& Greco, M. (1991). Some antecedents and consequences of yawning. Psychological Record, 41, 453-460.

BARBIZET, J. (1958). Yawning. Journal of Neurology, Neurosurgery \& Psychiatrv, 21, 203-209.

Barthalamus, G., \& Zielinski, W. (1988). Xenopus skin mucus induces oral dyskinesias that promote escape from snakes. Pharmacology, Biochemistry \& Behavior, 30, 957-959.

BerENDSEN, H. H., \& Nickolson, V. J. (1981). Androgenic influences on apomorphine induced yawning in rats. Behavioral \& Neural Biology, 33, 123-128.

Bertolini, A., Vergoni, W., Gessa, G. L., \& Ferrari, W. (1969). Induction of sexual excitement by the action of ACTH in brain. $\mathrm{Na}$ ture, 221, 667-669.

BERTRAND, M. (1969). The behavioral repertoire of the stumptail macaque. Basel: Karger.

Blanton, M. G. (1917). The behavior of the human infant during the first 30 days of life. Psychological Review, 24, 456-483.

Chambers, K. C., \& Phoenix, C. H. (1980). Diurnal patterns of testosterone, dihydrotestosterone, estradiol and cortisol in serum of rhesus males: Relationship to sexual behavior in aging males. Hormones \& Behavior, 15, 416-426.

Clemente, C. D. (1985). Gray's Anatomy (30th ed.). Philadelphia: Lea \& Febiger.

Cowan, A. (1978). Cholinergic link in yawning. Nature, 271, 187-188.

Craemer, F. (1924). Über Sodbrennen und Gähnen. Gastroenterologia Archiv für Verdauungskrankheiten, 33, 149-162.

DARWIN, C. (1873). Expression of emotions in animals and man. New York: Appleton.

DePutte, B. (1978). Étude du baillement chez deux espèces de Cercopithecidae: Recherche des facteurs du causalité et du fonction. Doctoral thesis, Universite de Rennes.

DeputTe, B. (1994). Ethological study of yawning in primates: I. Quantitative analysis and study of causation in two species of Old World monkeys (Cercocebus albigena and Macaca fascicularis). Ethology, 98, 221-245.

Donovan, B. T. (1978). The behavioral actions of the hypothalamic peptides: A review. Psychological Medicine, 27, 103-130.

Dourish, C. T., \& CoOper, S. J. (1991). Neural basis of drug induced yawning. In S. J. Cooper \& C. T. Dourish (Eds.), Neurobiology of stereotyped behavior (pp. 91-116). Oxford: Oxford University Press, Clarendon Press.

Dulbecco, R. (1991). Encyclopedia of human biology. San Diego: Academic Press.

DUMPERT, V. (1921). Zur Kenntnis des Wesens und der physiologischen Bedeutung des Gähnens. Journal für Psychologie und Neurologie, 27, 82-95.

Feldman, J. F., Brody, N., \& Miller, S. A. (1980). Sex differences in non-elicited neonatal behavior. Merrill-Palmer Quarterly, 26, 6373

Ferrari, W., Floris, E., \& Paulesu, F. (1955). Su di una particolare, imponente sintomalogia prodotta nel cane dall'ACTH iniettato nella cisterna magna. Bolletin della Società Italiana Biologica Sperimentale, 31, 862 .

Ferrari, W., Gessa, G. L., \& Vargiu, L. (1963). Behavioral effects induced by intracisternally injected $\mathrm{ACTH}$ and MSH. (Annals of the New York Academy of Sciences, Vol. 104, pp. 330-345). New York: New York Academy of Sciences.

Gessa, G. L., Pisano, M., Vargiu, L., Grabai, F., \& Ferrari, W. (1967). Stretching and yawning movements after intracerebral injection of ACTH. Revue Canadian de Biologie, 26, 229-236.

Gill, N. E., White, M. A., \& Anderson, G. C. (1984). Transitional 
newborn infants in a hospital nursery: From first oral cues to first sustained cry. Nursing Research, 33, 213-217.

Gower, A., Hemmie, H. G., Berendsen, M., Princen, M. C., \& BroekKamp, C. L. E. (1984). The yawning-penile erection syndrome as a model for putative dopamine autoreceptor activity. $E u$ ropean Journal of Pharmacology, 103, 81-90.

GoY, R. W., \& RESKO, G. A. (1972). Gonadal hormones and behavior of normal and pseudohermaphrodite nonhuman female primates Recent Progress in Hormonal Research, 28, 707-733.

Graybiel, A., \& KNEPTON, J. (1976). Sopite syndrome: A sometimes side manifestation of motion sickness. Aviation, Space, \& Environmental Medicine, 47, 873-882.

GRECO, M. (1992). Yawning facilitates the transition from lower to higher levels of arousal. Unpublished doctoral dissertation, Temple University.

Greco, M., \& BaEnninger, R. (1989). Self-report as a valid measure of yawning in the laboratory. Bulletin of the Psychonomic Society, 27, 75-76.

Greco, M., \& BAENNinger, R. (1991). Effects of yawning and related activities on heart rate and skin conductance. Physiology \& Behavior, 50, 1067-1069.

Greco, M., Baenninger, R., \& Govern, J. (1993). On the context of yawning: When, where, and why? Psychological Record, 43, 175-183.

GsCHWEND, J. (1977). Yawning in a case with transsecting glioma of the pons. Fortschritte der Neurologie, Psychiatrie und ihrer Grenzgebiete, 45, 652-655.

HADIDIAN, J. (1980). Yawning in an Old World monkey, Macaca nigra. Behaviour, 75, 133-147.

HALL, R. L. (1962). Behaviour of monkeys toward mirror images. Nature, 196, 1258-1261.

Hall, R. L., \& DeVore, I. (1965). Baboon social behavior. In G. DeVore (Ed.), Primate behavior (pp. 53-110). New York: Holt, Rinehart \& Winston.

HauptManN, H. (1920). Wie, wann, und wozu gähnen wir? Neurologie Zentralblatt, 23, 781-782.

Heusner, A. P. (1946). Yawning and associated phenomena. Physiological Review, 26, 156-168.

Hinde, R. A., \& Rowell, T. E. (1962). Communication by postures and facial expressions in the rhesus monkey, Macaca mulatta. Proceedings of the Zoological Society of London, 138, 1-21.

Holmgren, B., Budelli, R., Urba-Holmgren, R., Eguibar, J. R., Holmgren, M., Baz-Tellez, G., \& Anias, J. (1991). Food anticipatory yawning rhythm in the rat. Acta Neurobiologiae Experimentalis, 51, 27-35.

Holmgren, B., \& URba-Holmgren, R. (1980). Interaction of cholinergic and dopaminergic influences on yawning behavior. Acta Neurobiologiae Experimentalis, 40, 633-642.

Holmgren, B., Urba-Holmgren, R., Aguiar, M., \& Rodriguez, R. (1980). Sex hormone influences on yawning. Acta Neurobiologiae Experimentalis, 40, 515-519.

Holmgren, B., Urba-Holmgren, R., Trucios, N., Zermeno, M., \& Eguibar, J. R. (1985). Association of spontaneous and DA ergic induced yawning and penile erection in rat. Pharmacology, Biochemistry \& Behavior, 22, 31-35.

Huston, J. P. (1971). Yawning and penile erections induced in rats by cortical spreading depression. Nature, 232, 274-275.

JohNSON, W. H., \& JoNGKeEs, L. B. W. (1974). Motion sickness. In Handbook of sensory physiology: Vol. 6. Vestibular system: Pt. 2. Psychophysics, applied aspects and general interpretations (pp. 389. 404). Berlin: Springer-Verlag.

Karasawa, J., Kuriyama, Y, Kuro, M., Kikuchi, H, Sawata, T. \& Mitsugi, T. (1982). Monitoring system of cerebral blood flow and cerebral metabolism: 2. Relationship between internal jugular oxygen tension and cerebral blood flow. Brain-Nerve, 34, 239-245.

Koch, P., Montagner, H., \& Soussignan, R. (1987). Variation of behavioral and physiological variables in children attending kindergarten and primary school. Chronobiology International, 4, 525535

Konorski, J. (1967). Integrative activity of the brain. Chicago: University of Chicago Press

Lal, S., Grassino. A.. Thavundayil, J. X., \& Dubrovsky, B. (1987).
A simple method for the study of yawning in man induced by the dopamine receptor agonist apomorphine. Progress in Neuropsychopharmacology \& Biological Psychiatry, 11, 223-228.

LANTHORN, T. H., \& ISAACSON, R. L. (1979). Stretching and yawning: A role of glutamate. Psychopharmacology, 65, 317-318.

LAPING, N., \& Ramirez, V. (1986). Prolactin induces yawning and the stretch-yawning syndrome in young adult male rats. Hormones \& Behavior, 20, 49-59.

LASKIEWICZ, A. (1953). Yawning with regard to the respiratory organs and the ear. Acta Otolaryngology, 43, 267-270.

LEHMAN, H. (1979). Yawning: A homeostatic reflex and its psychological significance. Bulletin of the Menninger Clinic, 43, 123-136.

Louboungou, M., \& Anderson, J. R. (1987). Yawning, scratching, and protruded lips: Differential conditionability and natural acts in pigtail monkeys, Macaca nemestrina. Primates, 28, 367-375.

LUTTENBERGER, F. (1975). On yawning in reptiles. Zeitschrift für Tierpsychologie, 37, 113-137.

MARINI, J. (1981). Serotonergic and dopaminergic effects on yawning in the cat. Pharmacology, Biochemistry \& Behavior, 15, 711-715.

Mastripieri, D., Schino, G., Aureli, F., \& Troisi, A. (1992). A modest proposal: Displacement activities as an indicator of emotions in primates. Animal Behaviour, 44, 967-979.

MavjeE, V., \& HoRne, J. A. (1994). Boredom effects on sleepiness/ alertness in the early afternoon vs. early evening and interactions with warm ambient temperature. British Journal of Psychology, 85, 317-333.

McKFnZIE, A. (1994). The tonsillar evacuation hypothesis of yawning behaviour. South African Journal of Science, 90, 64-66.

MEAD, J., \& COLLIER, C. (1959). Relation of volume history of lungs to respiratory mechanics in anesthetized dogs. Journal of Applied Physiology, 14, 669-678.

Melis, M. R., Stancampiano, R., Lai, C., \& Argiolas, A. (1995) Nitroglycerin-induced penile erection and yawning in male rats Mechanism of action in the brain. Brain Research Bulletin, 36, 527 531.

Miller, E. H. (1975). A comparative study of facial expressions of two species of pinnipeds. Behaviour, 53, 264-268

Model., J. G. (1989). Repeated observations of yawning, clitoral engorgement, and orgasm associated with fluoxetine administration [Letter to the editor]. Journal of Clinical Pharmacology, 9, 63-65.

MoGiLnickA, E., \& KLIMEK, V. (1977). Drugs affecting dopamine neurons and yawning behavior. Pharmacologv, Biochemistry \& Behavior, 7, 303-305.

Moore, J. E. (1942). Some psychological aspects of yawning. Journal of General Psychology, 27, 289-294.

Moyaho, A., Eguibar, J. R., \& Diaz, J. L. (1995). Induced grooming transitions and open field behavior differ in high and low-yawning sublines of Sprague-Dawley rats. Animal Behaviour, 50, 61-72.

MyrberG, A. A. (1972). Ethology of the bicolor damselfish, Eupomacentrus partitus: A comparative analysis of laboratory and field behaviour. Animal Behaviour Monographs, 5, 197-283.

Nakanishi, K., Hinoki, M., Ito, S., Izumikawa, F., \& Baron, J. B. (1980). Kinetic troubles (car sickness) in patients with scoliosis. Agressologie, 21, 47-60.

Nicholas, T. E., Power, J. H. T., \& Barr, H. A. (1982). The pulmonary consequences of a deep breath. Respiration Physiology, 49, 315 324.

O'BriEn, C. P. (1976). Experimental analysis of conditioning factors in human narcotic addiction. Pharmacological Review, 27, 533-543.

Opp, M. R., Obal, F., \& Krueger, J. M. (1988). Effects of alpha MSH on sleep. behavior, and brain temperature: Interactions with $\mathrm{IL} 1$. American Journal of Physiologv, 255 (6. Pt. 2), R914-922.

PACKER, C. (1979). Male dominance and reproductive activity in Papio anubis. Animal Behaviour, 27, 37-45.

Phoenix, C., \& Chambers, K. (1982). Sexual behavior in adult gonadectomized female pseudohermaphrodite, female and male rhesus macaques treated with extradiol benzoate and testosterone propionate. Journal of Comparative \& Physiological Psychology, 96 823-833.

PlageT, J. (1951). Play, dreams and imitation in childhood. New York Norton. 
Proctor, D. F. (1964). Physiology of the upper airway. In W. O. Fenn \& H. Rahn (Eds.), Handbook of physiology: Vol. I, Respiration (pp. 307-345). Washington, DC: American Physiological Society.

Provine, R. R. (1986). Yawning as a stereotyped action pattern and releasing stimulus. Ethology, 72, 109-122.

Provine, R. R., \& Hamernik, H. B. (1986). Yawning: Effects of stimulus interest. Bulletin of the Psychonomic Society, 24, 437-438.

Provine, R. R., Hamernik, H. B., \& CurChaCk, B. C. (1987). Yawning: Relation to sleeping and stretching in humans. Ethology, 76, 152-160.

Provine, R. R., TATE, B., \& Geldmacher, L. (1987). Yawning: No effect of $3-5 \% \mathrm{CO}_{2}, 100 \% \mathrm{O}_{2}$ and exercise. Behavioral \& Neural Biology, 48, 382-393.

RASA, O. A. (1971). The causal factors and functions of yawning in M. chrysurus (Pisces: pomacentridae). Behaviour, 39, 39-57.

REDICAN, W. K. (1975). Facial displays in non-human primates. In L. A Rosenblum (Ed.), Primate behavior: Developments in field and laboratory research (Vol. 4, pp. 103-194). New York: Academic Press.

Rodriguez, R., Serra, J. F., Terrasawa, E., Goldfoot, D. A., \& DEWIED, D. (1981). Testosterone potentiation of effectiveness of ACTH 1-24 on induction of stretch-yawn syndrome in male guinea pigs. Hormones \& Behavior, 15, 77-85.

RudolPh, A. M., Barnett, H. L., \& Einhorn, A. H. (Eds.) (1977). Pediatrics (16th ed.). New York: Appleton Century Crofts.

Salamone, J. D., Lalies, M. D., Channell, S. L., \& Iversen, S. D. (1986). Behavioral and pharmacological characterization of the mouth movements induced by muscarinic agents in the rat. Pharmacology, 88, 467-471.

SAUER, E. G., \& SAUER, E. M. (1967). Yawning and other maintenance activities in the South African ostrich. Auk, 84, 571-587.

SCHINO, G., \& AURELI, F. (1989). Do men yawn more than women? Ethology \& Sociobiology, 10, 375-378.

Serra, G., Collu, M., Loddo, S., Cel.asco, G., \& Gessa, G. L. (1983). Hypophysectomy prevents yawning and penile erection but not hypomotility induced by apomorphine. Pharmacology, Biochemistry \& Behavior, 19, 917-920.

Sherer, D. M., Smith, S. A., \& Abramowicz, J. S. (1990). Fetal yawning in utero. Journal of Clinical Investigation, 68, 176-177.

Skorzewska, A., Tesfaye, Y., Krishnan, B., Schwartz, G., ThavunDAYIL, J., \& LAL, S. (1993). Effect of scopolamine on spontaneous yawning in men. Neuropsychobiology, 27, 17-20.

SMALL, M. M. (1977). Covert discrimination training: An experimental test of the assumed functional equivalence between covert and overt conditioning procedures. Psychological Reports, 41, 715-720.

Smotherman, W. P., \& Robinson, S. R. (1987). Prenatal expression of species typical action patterns in the rat fetus. Journal of Comparative Psychology, 101, 190-196.

TAYLOR-JONES, L. (1927). A study of behavior in the newborn. American Journal of Medical Science, 174, 357-362.

THACH, B. T., \& TAEUSCH, H. W. (1976). Sighing in newborn infants: Role of inflation augmenting reflex. Journal of Applied Physiology, 41, 502-507.

Thet, L. A. L., Clerch, G. D., Massaro, A., \& Massaro, D. (1979). Changes in sedimentation of surfactant in ventilated excised rat lungs. Journal of Clinical Investigation, 64, 600-608.

THORNDIKE, E. L. (1911). Animal intelligence. New York: Macmillan. TINBERGEN, N. (1963). On aims and methods of ethology. Zeitschrift für Tierpsychologie, 20, 410-429.

Troisi, A., Aureli, F., Schino, G., Rinaldi, F., \& DeAngeli, N. (1990). The influence of age, sex, and rank on yawning behavior in two species of macaques (fascicularis and fuscata). Ethology, 86, 303-310.

TSUNETOMO, Y. (1979). Hagakure: The book of a Samurai. Tokyo: Kodansha International.

Urba-Holmgren, R., Gonzalez, R. M., \& Holmgren, B. (1977). Is yawning a cholinergic response? Nature, 267, 261-262.

Urba-Holmgren, R., Holmgren, B., Rodriguez, R., \& Gonzalez, R. M. (1979). Serotonergic modulation of yawning. Pharmacology, Biochemistry \& Behavior, 11, 371-372.

Urba-Holmgren, R., Trucios, N., Holmgren, B., Eguibar, J. R., Gavito, A., CruZ, G., \& SANTos, A. (1990). Genotypic dependency of spontaneous yawning frequency in the rat. Behavioral \& Brain Research, 40, 29-35.

UshiJima, I., Yamada, K., InOUE, T., TokUnaga, T., \& FurukaWa, T. (1984). Muscarinic and nicotine effects on yawning and tongue protruding in the rat. Pharmacology, Biochemistry \& Behavior, 21, 297-301.

Van Woerden, E. E., Van Geijn, H. P., Caron, F. J., Van der Valk, A. W., SwartJes, J. M., \& ARTS, N. F. (1988). Fetal mouth movements during behavioral states $\mathrm{IF}$ and $2 \mathrm{~F}$. European Journal of $\mathrm{Ob}$ stetrics, Gynecology \& Reproductive Biology, 29, 97-105.

Yamada, K., \& FuruKaWA, T. (1980). Direct evidence for involvement of dopaminergic inhibition and cholinergic activation in yawning. Psychopharmacology, 67, 39-43.

YAMADA, K., \& FuruKaWA, T. (1981). The yawning elicited by alpha MSH involves serotonergic-dopaminergic-cholinergic link in rats. Naunyn-Schmiedeberg's Archives of Pharmacology, 316, 155-160.

(Manuscript received November 8, 1995; revision accepted for publication November 15,1996 .) 